\title{
Performance and Retrofitting of Unreinforced Masonry Buildings against Natural Disasters - A Review Study
}

\author{
W. S. W. Mendis, Sudhira De Silva and G. H. M. J. Subashi De Silva
}

\begin{abstract}
Un-Reinforced Masonry (URM) buildings are popular all over the world including Sri Lanka because of their durability, low cost, construction easiness and architectural character, need of less skilled labour, eco-friendliness and use of locally available materials such as ashlar or rubble, adobe and brick. However, these buildings have a higher probability of failing under natural disasters such as earthquakes, tsunamis and storm surges, floods, cyclones and landslides. In Sri Lanka, winds, landslides and floods have frequently occurred. In addition, a massive tsunami adversely affected the people in 2004 and its effects to islands on the Indian Ocean have been continued since December, 2004. Minor earthquakes have come off recently with experiences of wall cracks and no deaths. It is also believed that, there is a defused plate boundary in the making some $500 \mathrm{~km}$ south of the southern tip of Sri Lanka which might be the cause of these tremors or minor quakes. Further, an earthquake occurred in Colombo area in 1615, has caused around 2000 of human deaths. Therefore investigation of performance of URM buildings against these natural disasters and possible retrofitting methods are increasingly important.
\end{abstract}

In this review study, an attempt is made to identify the performance of URM buildings against natural disasters and identify retrofitting methods that can be applied to existing building, to enhance the strength properties of structural components. Common failure mechanisms for URM structures consist of separation of walls at corners, diagonal cracking or vertical cracking in walls, separation of roofing from walls, out-of-plane wall failure, in-plane wall failure, shear cracks and de-lamination. These damages on a wall diminish the service life of building. In addition, different kinds of retrofitting methods: ferrocement, poly propylene mesh and bamboo reinforcement, for URM structures to be seismic resistant are presented. Mechanisms of failure of URM walls and effects of retrofitting techniques to reduce the damage are also discussed.

Keywords: Un-Reinforced Masonry (URM) buildings, retrofitting, natural disasters, failure mechanisms, control mechanisms

\section{Introduction}

Throughout the centuries, natural disasters have taken a high toll of human lives and caused great property losses all over the world and unfortunately mostly in developing countries. The worst death toll from an earthquake, in the past century, occurred in 1976 in China, where it is estimated that 240,000 people were killed and most of the deaths were due to the collapse of brick masonry buildings (D'Ayala [11]). Further, Sri Lanka had also experienced a tsunami in 26 $6^{\text {th }}$ December, 2004 which caused large amount of deaths and damages. Most of the damaged structures in Sri Lanka were domestic buildings, which had been constructed using masonry (i.e., bricks or cement sand blocks).

A natural hazard is said to be a natural disaster when the hazard affects humans and the built environment. Natural hazards (i.e. earthquakes, landslides, volcanic eruptions, floods and cyclones), will never result in a natural disaster in areas without vulnerability. Therefore, the financial, environmental or human loss resulted from a disaster depends on capacity of the population to resist the disaster. Besides natural disasters, there are also man-made disasters which are the results of technological or human hazards such as fires, transport accidents,

Ms. W.S.W. Mendis, B.Sc. (Hons) (Ruhuna), Rresearch Student, Department of Civil and Environmental Engineering, Faculty of Engineering, University of Ruhuna, Sri Lanka.

Eng. (Dr.) Sudhira De Silva, PhD (Saitama), M.Eng (Saitama) B.Sc. Eng. (Hons) (Moratuwa), C.Eng. MIE (Sri Lanka), Senior Lecturer, Department of Civil and Environmental Engineering, Faculty of Engineering, University of Ruhuna, Sri Lanka.

Eng. (Dr.) (Mrs). G. H. M. J. Subashi De Silva, PhD (Saitama), B.Sc. Eng. (Hons) (Moratuwa), C.Eng. MIE (Sri Lanka), Senior Lecturer, Department of Civil and Environmental Engineering, Faculty of Engineering, University of Ruhuna, Sri Lanka. 
industrial accidents, oil spills and nuclear explosions. Further, earth cutting, which is mechanically excavated or blasted out with carefully placed explosives, often causes landslides, if appropriate protective measures are not provided. Piling work, which has been provided as a support for a structure, also induces ground vibration. These vibrations disturb residents at near area in a manner similar to an earthquake. The economic cost of natural disasters over the last ten years in Sri Lanka exceeded LKR 257 billion, (i.e., USD 1.95 billion) (Rajasingham [29]).

In Sri Lanka, natural disasters such as minor earthquakes, tsunami and storm surges, floods, cyclones and landslides are encountered. Apart from the environmental implications, deforestation in Sri Lanka has caused ill effects such as flooding, landslides and soil erosion from exposure of the deforested areas (Keerthisinghe [21]). Weather changes in Sri Lanka showed that, not only landslides and floods (originated with precipitation), but also extreme wind events have frequently occurred. Minor earthquakes have come off recently with experiences of only wall cracks and no human death. Besides, it is believed that, there is a defused plate boundary in the making some $500 \mathrm{~km}$ south of the southern tip of Sri Lanka (Dissanayake [14]). Sri Lankans were adversely affected by the tsunami created by the earthquake that occurred in the coastal zone near Sumatra Island in December, 2004 with a huge catastrophe to human lives. Reasons for such a loss of human lives are that, people have no awareness on behaving in a disaster and the collapse of man-made buildings or structures resulted in most of the deaths.

In general, buildings can be divided into two main categories: engineered buildings and nonengineered buildings. Their percentages are quite different in developed, developing, and under-developed countries. Past destructive disasters have showed that non-engineered buildings were the one which have been damaged mostly. Skilled technicians, engineers and architects are generally not involved in this type of construction (Blondet et al. [7]). In Sri Lanka, most of dwellings are non-engineered buildings constructed as URM buildings. URM buildings are popular because of having inherent advantages such as durability, low cost, construction easiness and architectural character, need of less skilled labour, use of locally available materials, eco-friendliness, heat and sound insulation and fire resistance.
The damages of structures due to natural disasters are encountered day to day and these damages cause structural failures, casualties and deaths. Therefore, investigation of performance of URM buildings and introducing required retrofitting methods to improve their resistance against natural disasters are increasingly important.

Objectives of the current study are to review published literature and,

- Identify performance of URM buildings against natural disasters

- Identify retrofitting methods that can be applied to existing building, to enhance the strength properties of structural components, decrease the amount of damage and enhance the time duration for collapse, which helps people to evacuate

However, a suitable retrofitting technique for Sri Lanka should be efficient not only in improvement of seismic resistant characteristics such as strength, ductility, but also in economy and availability of construction materials and required labour skills. Damage patterns and causes for strength losses in URM buildings due to natural disasters (i.e., earthquakes, tsunami and floods) are identified and presented in this paper. In addition, retrofitting methods that can be applied to unreinforced masonry buildings in Sri Lanka, so as to resist dynamic loads induced by earthquakes, tsunamis and floods are also presented.

\section{Damages in URM Buildings}

From the observation of structural performance of buildings during an earthquake, the strong and weak aspects of the design as well as the desirable qualities of materials, construction techniques and site selection can be clearly identified (Boen [8]). This can be applied to other natural disasters as well and the study of damages provides an important step in the evolution of strengthening measures for URM buildings.

The most of damages in dwelling houses occurred because of the poor designing and construction. It has been reported that the most important weaknesses of the masonry structures were the lack of interlocking units between external and internal wythes of the wall sections and the lack of connection between crossing walls (Velazquez-Dimas et al. 
[36]). Both of them give rise to possibility of out-of-plane behaviour, as their formation increases net length of the walls. Also, roof placed directly on the walls without bond beams does not provide a diaphragm and due to free end at the top of walls, probability of out-of-plane failure mechanisms increases. Placement of openings near the corners of the walls is another common problem where crack propagation is concentrated around these openings. With the mass of evidence from past earthquakes, tsunamis and floods, the typical damages to URM buildings are discussed, below.

\subsection{Damages Due to Earthquake}

During earthquakes, the ground shakes in all directions and generates inertia forces that the structure should be able to withstand. Under seismic loading, URM walls have two main possible failure mechanisms: in-plane and outof-plane (Saatcioglu et al. [32]). In-plane failures are characterized by a diagonal tensile crack pattern while out-of-plane failures are characterized by cracks that are primarily along the mortar bed joints. The principal in-plane failure mechanisms of URM walls subjected to earthquake actions are shear failure, sliding failure, rocking failure and toe crushing (Figure 1).
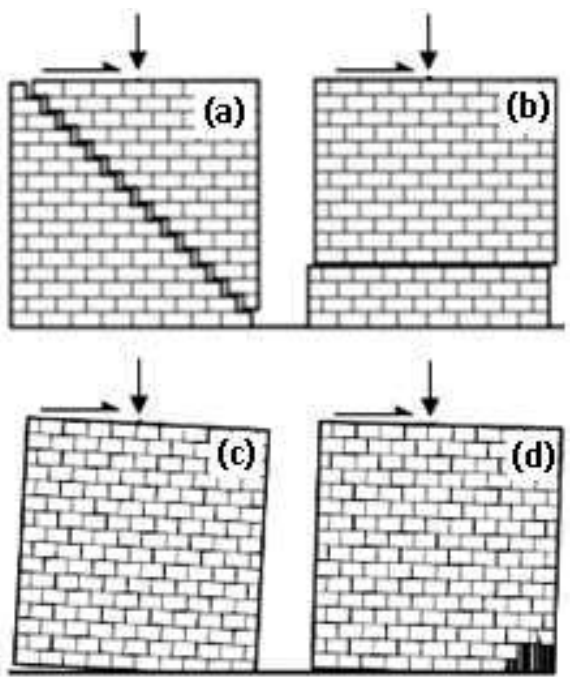

Figure 1- In-plane failure modes of a laterally loaded URM wall (ElGawady et al. [19]):

(a) Shear failure, (b) Sliding, (c) Rocking, (d) Toe crushing

The typical out-of-plane failure patterns of URM wall resulted from an earthquake are shown in Figure 2.

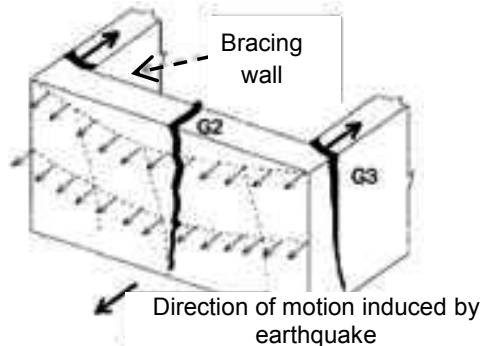

\section{Figure 2 - Typical crack patterns of URM buildings due to out-of-plane failure}

(Bartolome et al. [4])

The performance of small adobe and lowquality mud-brick constructions varied from no damage to collapse and, within any specific area, the performance of these buildings depended on a number of parameters, including wall thickness, roof mass, size of rooms, and quality of materials (Webster [37]). Earthen structures have less ductility and are very brittle resulting in sudden failures under seismic loading without any warning.

The traditional earthen buildings are vulnerable due to a perverse combination of the mechanical properties of their walls where earthen walls are dense and heavy, have extremely low tensile strength resulted from weak material, lack of reinforcement, poor workmanship and null maintenance (Bartolome et al. [5] and Blondet et al. [7]). Common failure modes of adobe structures were reported by Blondet et al. [6] (Figure 3). The same failure modes can be expected for other types of masonry buildings (Bartolome et al. [4] and [5], Blondet et al. [7], D'Ayala [11] and Kaplan et al. [20]) (Figure 4).

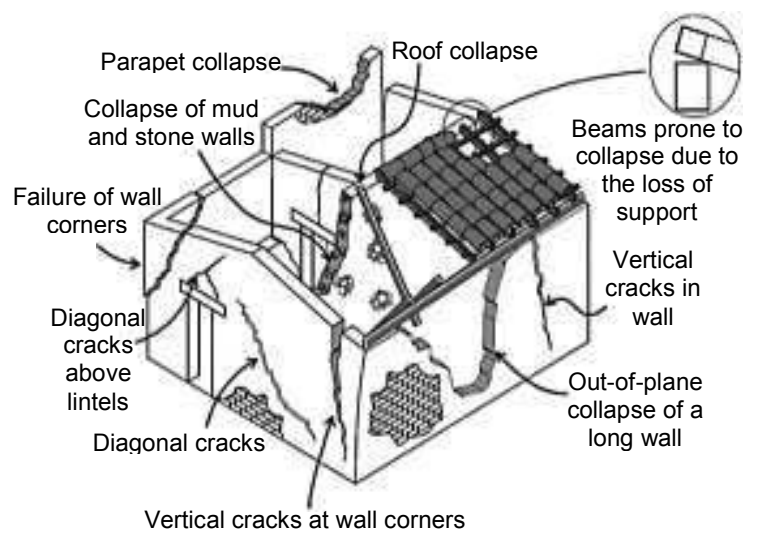

Figure 3 - Seismic deficiencies of adobe masonry (Blondet et al. [6])

Since the tensile strength is very low, significant cracking starts (with the initiation of an earthquake) in the regions subjected to tension. Vertical cracking starts at the lateral corners of 
the walls, where the tensile stresses are higher due to out-of-plane bending produced by seismic forces perpendicular to the walls (Figures 2 and 3). The continuity of ground movement produces large vertical corner cracks, which tend to separate the walls from one another (Figures 2 and 3). Shear forces generated by lateral seismic forces acting within the plane of the walls, produce diagonal cracks, which usually follow stepped patterns along the mortar joints (Figures 1and 3). Due to the stress concentration at the corners of openings (i.e., doors and windows), diagonal cracks often start at these locations (Figure 3).

Front walls are, usually the first to collapse in an earthquake, overturning onto the adjacent street (Blondet et al. [7]) as shown in Figure 4(a) and $(b)$.

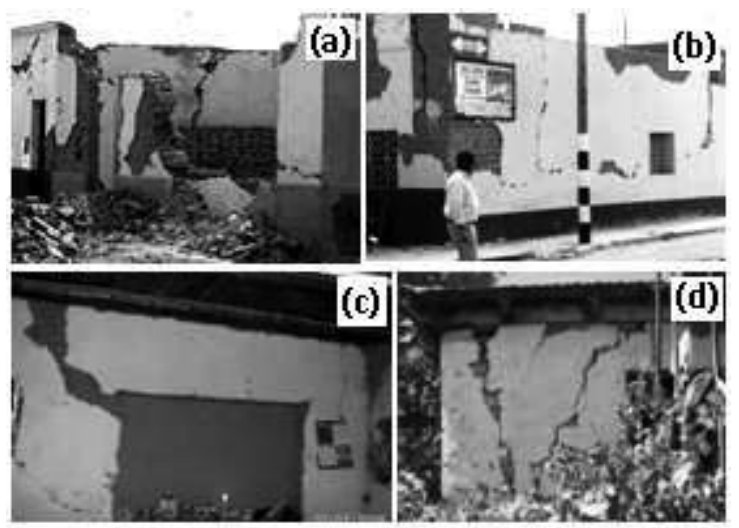

Figure 4 - Seismic cracks in URM houses:

(a) Collapse due to out-of-plane failure (severe earthquakes in Peru) (Bartolome et al. [4]),

(b) Typical cracks on adobe houses due to out-of-plane seismic forces (Bartolome et al. [4]),

(c) Shear cracks initiated at the corners of openings in wall of house in La Tinguiña (in-plane failure) (Bartolome et al. [5]),

(d) Wall-diagonal crack and vertical corner crack (both in-plane and out-ofplane failure) (Kaplan et al. [20])

According to Blondet et al. [7], earthen houses built without any structural reinforcement, with several stories, thin walls, large window and door openings, and irregular plan and elevation configurations are extremely vulnerable and suffer significant damage or collapse during earthquakes.

\subsection{Damages Due to Tsunami}

Damages of URM buildings by tsunami effects could be due to hydrostatic, hydrodynamic, impulsive, impact and buoyancy forces (Figure
5). Both static and dynamic loads are dependent on wave height as wave velocity is related to its height (Dias et al. [13]). Therefore depending on the wave height, damage level can be differed in various types of structures. It has been found that most single storied masonry structures completely pushed off their foundations in sliding mode, due to no tying down of structure and less self weight caused by thin wall $(130 \mathrm{~mm})$ of half brick (Dias et al. [13]). Renuka and Lewangamage [30] found that main failure types in URM structures were bending, diagonal tension and compression, overturning and sliding (Figure 6), by conducting a Finite Element Modeling (FEM) of single storied and two storied houses while Dias et al. [13] have also stated that overturning and sliding are two of main threats from tsunami wave on a structure.
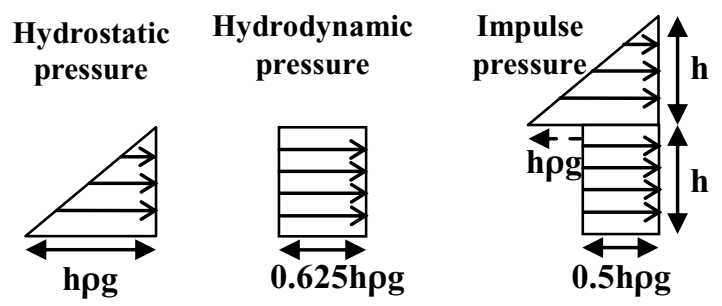

Figure 5 - Components of tsunami induced forces, where $h$ is inundation depth, $\rho$ is density of water and $g$ is gravitational acceleration (Renuka and Lewangamage [30])

The URMs performed very poorly in resisting the lateral forces of the tsunami. Bending capacity of unreinforced brick masonry was very low against the hydrostatic forces of the tsunami (Maheshwari et al. [26] and Renuka and Lewangamage [30]). Overturning moment increases with higher pressure while higher building weight and gravel type soil around base will reduce the overturning effect.
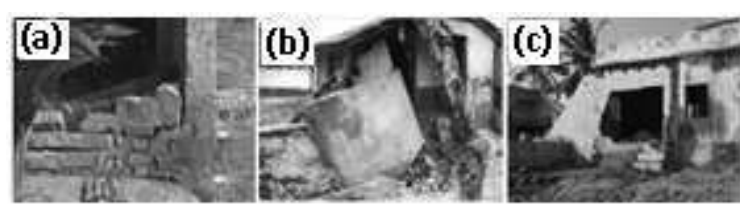

Figure 6 - Damage to URM buildings by

December 26, 2004 Sumatra Earthquake:

(a) Brick masonry walls in Talenguda-sliding failure (Maheshwari et al. [26]), (b) Brick masonry in Trincomalee- overturning due to foundation scouring (Khazai et al. [23]), (c) Buildings in Meelamanakudy- bending failure (Maheshwari et al. [26]) 


\subsection{Damages Due to Flooding}

Damages of URM structures by a flood resulted from storm surge, riverine flooding, or urban flooding mainly occur due to physical forces such as hydrostatic loads, hydrodynamic loads, impact loads and buoyancy (Figure 7) (Caraballo-Nadal et al. [9] and Rogers [31]).

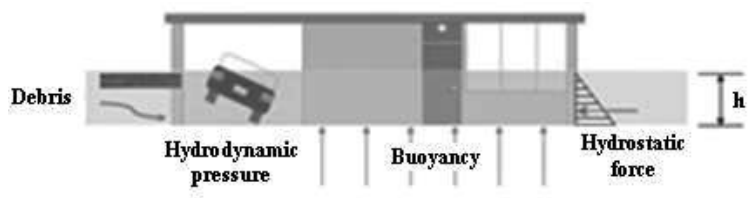

Figure 7 - Typical forces generated by flooding (Caraballo-Nadal et al. [9])

Lateral hydrostatic forces are generally not sufficient to cause deflection or displacement of a building unless there is a significant difference in water elevation on opposite sides of the wall in contact with the flood water. However, if there is significant difference, permanent deflections and damage to structural elements within the building may occur. Hydrodynamic forces are a function of flood water velocity and the building geometry and are capable of collapsing structural walls or floor systems. Figure 8 shows failure of a URM wall due to influence of flood water.

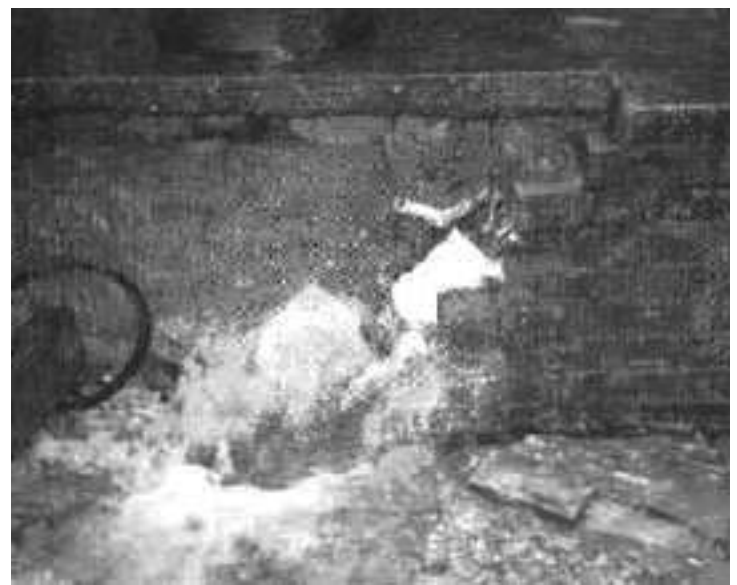

Figure 8 - Brickwork wall broken by flood water, Malton, U.K., November 2000

(Kelman and Spence [22])

When the buoyant forces, which are also called as vertical hydrostatic force, associated with the flood, exceed the weight of the building components and the connections to the foundation system, the structure may float from its foundation. The force acted vertically through the centre of mass of the displaced volume. Impact loads are the direct forces associated with waves, as typically encountered during coastal flooding, or the impact of floating debris (Figure 9) within the flood waters. These loads are especially destructive because the forces associated with them may be higher in magnitude than the hydrostatic and hydrodynamic forces.

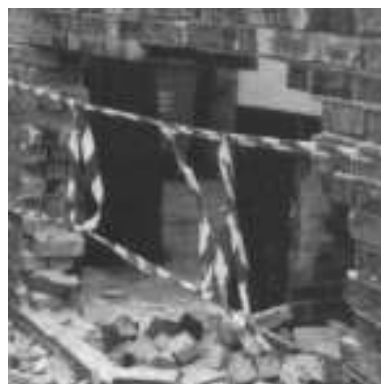

Figure 9 - Brickwork wall damaged due to impact force, Cambridge, U.K., December 2001 (Kelman and Spence [22])

Kelman and Spence [22] found that the vertical and diagonal yield lines comprise a sequence of horizontal and vertical segments (Figure 10) due to failure along the mortar joints rather than through the masonry units from conducting a yield line analysis for URM failing due to flood water pressures resulted from the combination of hydrostatic and hydrodynamic forces using small (area $=38 \mathrm{~m}^{2}$ ), medium (area $=55 \mathrm{~m}^{2}$ ) and large $\left(\right.$ area $=84 \mathrm{~m}^{2}$ ) cavity wall dwellings in U.K. This result is also confirmed from practical situations shown in Figures 8 and 9.

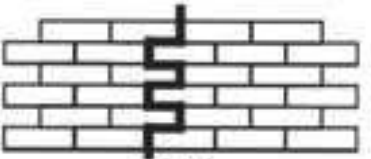

(a)

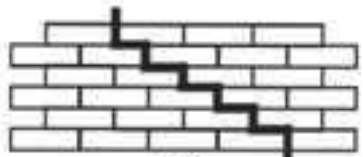

(b)
Figure 10 -Yield line in brick work (Kelman and Spence [22]): (a) Vertical yield line and (b) Diagonal yield line

Khazai et al.[23] found that, URM walls would collapse, if height difference of $1-1.5 \mathrm{~m}$ in opposite directions of the wall with no flood velocity. With flood velocity, the height difference in opposite directions of the wall for collapse can be below $0.5 \mathrm{~m}$ for some masonry walls.

\section{Retrofitting Techniques}

Retrofitting techniques are usually introduced to prevent the sudden collapse of buildings during natural disasters allowing people to evacuate (Bartolome et al. [4]). Retrofitting will upgrade the disaster resistance of an existing unsafe building, or a damaged building while repairing (Arya [2]). Though it may not be 
designed to be totally disaster-resistant but to avoid its collapse, adequate reinforcements should be provided. Seismic retrofitting techniques for URM buildings that have been studied in previous studies are ferrocement, PP-band mesh, bamboo reinforcement, old tire strip, FRP, steel strip mesh and diagonal steel bracings (Figure 11).

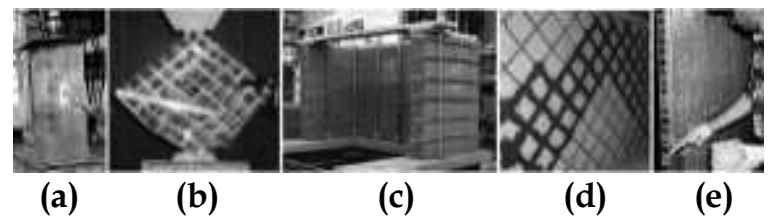

Figure 11 - Retrofitting techniques:

(a) Ferrocement (Shah [34]), (b) PP-band mesh reinforcement in testing stage (Sathiparan et al. [33]), (c) External horizontal bamboo (outside), external vertical bamboo (inside), internal horizontal chicken wire mesh and ring beam (Dowling et al. [15]), (d) Old tire strips (Kaplan et al. [20]), (e) Application of FRP reinforcement (Velazquez-Dimas [36])

\subsection{Retrofitting of URM Buildings against Earthquakes}

The range of earthquake magnitude that may affect the country region should also be considered when introducing or selecting a retrofitting technique for existing and damaged URM buildings and, when introducing seismic resistant features for building construction. This is to eliminate unnecessary time and money wasting. In Sri Lanka, earth tremors of magnitude of less than 5 on Richter scale have been reported, in some areas in Nuwara Eliya, Buddulla, Matara, Galle, Ratnapura, Kalutara, Colombo, Hambantota, Ampara and Monaragala districts (De Silva [12]). A technique to be used to strengthen structures must be compatible with economy of the particular country as well as efficient in seismic resistant against particular range of earthquakes that the country could be affected. Therefore, three retrofitting techniques: ferrocement, poly-propylene band mesh and bamboo reinforcement, are explained where they meet with the economic feasibility in rural area, technology skills of labourers in Sri Lanka and level of required resistant level against earthquakes.

In addition, there are other retrofitting techniques: Fiber Reinforced Polymer (FRP) laminating (Ehshani and Saadatmanesh [16], Ehshani et al. [17] and ElGawady et al. [18])), steel bracketing and introducing columns and tie beams (frame structure), which give higher earthquake resistant to the building. These three techniques seemed to be very expensive and needed specialized labour for installation; therefore, suitable for urban areas and where structure is more valuable. Also, making a frame structure with reinforced columns and tie beams and infilling the frame using masonry or concrete blocks can be seen in building construction for residents in urban areas in Sri Lanka.

\subsubsection{Ferrocement}

Ferrocement is a composed of steel wire mesh that is completely penetrated with a mortar which is rich in cement. The mortar is a mixture of sand, water and cement where sand particle size is not bigger than about $5 \mathrm{~mm}$. The wire mesh is very thin and the wires are closely spaced (i.e., commonly named as "chicken mesh"). Several layers of meshes can also be used.

Effect of ferrocement has been evaluated by Shah [34] by conducting an experiment under axial compression (Figure 11-(a)) using twenty one masonry columns of $221 \mathrm{~mm} \times 221 \mathrm{~mm} x$ $784 \mathrm{~mm}$ and they were tested. He found that, encasement of unreinforced masonry brick columns with ferrocement cover of $6.125 \mathrm{~mm}$ thickness and 1:2 cement sand mortar with water cement ratio of 0.5 and mesh spacing of $12.25 \mathrm{~mm}$, increased the ultimate failure load $121 \%$ or 1.33 times. Importantly, test results have showed that, failure of columns initiate only after failure of the casing. Ferrocement can also be used to repair columns, which have been loaded close to failure. The method discussed in Sha [35] can be applied in masonry walls as columns and walls are nearly similar in behaviour theoretically and practically.

Shahzaada et al. [35] found that retrofitting method of ferrocement overlay (i.e., with 12.5 $\mathrm{mm}$ pitched steel wire mesh and $5 \mathrm{~mm}$ thick 1:2 cement-sand mortar overlay) improved the overall strength of unreinforced brick masonry walls by $48 \%$ and also increased their ductility and avoided brittle failure as observed is compressive loading on twenty brick masonry walls size $20 \times 16 \times 9$ inch $^{3}$ (i.e., 508 mm x 406.4 $\mathrm{mm} \times 228.6 \mathrm{~mm}$ ).

A kind of in-plane cyclic loading test of increasing intensities with constant vertical loading has been carried out on URM walls (i.e., with size of $3087 \mathrm{~mm}$ x $3262 \mathrm{~mm}$ x 225 $\mathrm{mm}$ ) before and after retrofitting by 
ferrocement overlay by Ashraf et al. [3]. As they have stated, lateral in-plane strength and lateral stiffness of the URM wall could be increased by $110 \%$ and $68 \%$, respectively after retrofitting the wall by ferrocement overlay of $12.5 \mathrm{~mm}$ mesh pitched steel welded wire mesh (i.e. $1.0 \mathrm{~mm}$ diameter wires) and $19 \mathrm{~mm}$ thick 1:3 cement sand mortar.

These methods are simple, cost effective, required low technology and adding limited mass to the existing structure.

\subsubsection{Poly-Propylene Packaging (PP-band) Strip Mesh Reinforcement}

Poly propylene bands have been proposed as a cost-effective retrofitting material in Japan (Meguro et al. [28]). The method is simple, cost effective with no requirement of special technology and knowledge. Polypropylene is durable, inexpensive, harde and available worldwide. This material has no corrosion or insect failure effect and possesses excellent resistance to organic solvents and degreasing agent as well as electrolytic attack.

The behavior of walls strengthened with various PP-band mesh arrangements have been studied by Macabuag et al. [25] using diagonal compression test on both full scale and $1 / 4$ scale wallets. They found that PP-band mesh helps masonry walls to enhance the diagonal shear capacity and deformation by 2.75 times and 15 times those of URM walls without retrofitting.

To determine the resistance to in-plane and outof-plane loading, diagonal compression (Figure 11) and flexural bending, tests for PP mesh reinforced wallets and unreinforced wallets have been conducted (Sathiparan et al. [33]). The diagonal compression tests showed that PP mesh strengthened walls provide higher residual strength after formation of the first diagonal shear cracks. The out-of-plane tests also indicated the effectiveness of PP mesh after the walls have cracked. The strength and deformation of PP mesh reinforced walls were 2 times and 70 times those of the un-retrofitted wallets, respectively in diagonal compression tests. In out-of-plane bending tests, they were 2 times and 25 times respectively.

Mayorca et al. [27] have carried out a series of lateral reversed in-plane shear test on clay brick masonry walls and proved that although the mesh does increase the peak strength before initial failure, it contributes to improve wall's performance including the post peak strength after the first crack occurrence. This statement is as similar as the conclusion regarding masonry wall with PP-band mesh, given by Macabuag et al. [25] and Sathiparan et al. [33].

These tests (Macabuag et al. [25], Sathiparan et al. [33] and Mayorca et al. [27]) proved that initial failure stress is unaffected by the presence of the PP mesh due to the much lower stiffness of PP mesh compared to masonry; but, after the initial masonry failure, retrofitted walls continue to maintain the load and even avoid the sudden collapse and brittle failure.

Residual strength after crack initiation and residual stiffness of masonry wall retrofitted with PP-band mesh are directly proportional to PP-band density up to an optimum value and afterwards, they do not increase with the PPband density (Sathiparan et al. [33]). It can be said that this is due to the fact that the behaviour of masonry walls retrofitted with PPbands is effected not only by the effect of PPbands, but also the combination of both masonry and bands as a composite.

Looseness of the PP-band attachment with specimen reduces the residual strength after crack initiation of the specimen. However, an application of surface finishing gives a beneficial effect in residual strength (Sathiparan et al. [33]). Further, vertical bands mainly redistribute load through the specimen but offer little support, and horizontal bands offer little redistribution of load but directly bear the load to prevent loss of debris (Macabuag et al. [25]).

\subsubsection{Bamboo Reinforcement}

Dowling et al. [15] suggested that a significant improvement in the earthquake resistance of adobe mud-brick structures can be obtained by using external vertical and horizontal bamboo reinforcement, internal horizontal chicken wire mesh reinforcement and a ring beam (Figure 11-(c)). They tested five 1:2 scale u-shaped adobe mud-brick walls; each $150 \mathrm{~mm}$ thick, $1800 \mathrm{~mm}$ wide and $1200 \mathrm{~mm}$ high. One of them was a control specimen with no retrofitting and others were retrofitted: one with only corner pilasters; one specimen with internal horizontal chicken wire mesh, external vertical bamboo (inside and outside) and timber ring beam; one specimen with internal vertical bamboo reinforcement, internal horizontal chicken wire mesh and a timber ring beam; and another 
specimen with external vertical (inside) and horizontal (outside) bamboo reinforcement, internal horizontal chicken wire mesh and a timber ring beam. Each specimen was identified as summarized in Table 1. A downward restraining pressure loading of 125 $\mathrm{kPa}$ was applied to the top of the 'wing' walls (acting as in-plane shear walls) of all specimens by tension bars between timber plates and beam resting on the walls, and the concrete base.

Table 1- Specification of $\mathbf{u}$-shaped wall units (Dowling et al. [15])

\begin{tabular}{|c|l|}
\hline Specimen & \multicolumn{1}{c|}{ Description } \\
\hline 3A & Unreinforced, traditional \\
\hline 3B & Corner pilasters/buttresses only \\
\hline 3E & $\begin{array}{l}\text { Internal horizontal chicken wire } \\
\text { mesh (every three courses), } \\
\text { External vertical bamboo (inside } \\
\text { and outside), Timber ring beam }\end{array}$ \\
\hline 3G & $\begin{array}{l}\text { Internal horizontal chicken wire } \\
\text { mesh (every three courses), } \\
\text { Internal vertical bamboo, } \\
\text { Timber ring beam }\end{array}$ \\
\hline 3I & $\begin{array}{l}\text { Internal horizontal chicken wire } \\
\text { mesh (every three courses), } \\
\text { External vertical bamboo (inside), } \\
\text { External horizontal bamboo } \\
\text { (outside),Timber ring beam }\end{array}$ \\
\hline
\end{tabular}

The specimens were subjected to transient dynamic loading using the uni-axial shaking table to evaluate the response to out-of-plane seismic forces. Test results indicated that significant improvement in the earthquake resistance of adobe mud brick structures can be obtained by using technique specification used in 3I specimen. Although the specimen has showed severe damage at $(100 \%) \times 4$ intensity time-scaled simulation of the January 13, 2001 El Salvador earthquake (which possessed magnitude of 7.7 on $\mathrm{Mw}$ (moment magnitude scale)), the collapse of wall was not imminent.

In order to evaluate the effectiveness of the bamboo band mesh retrofitting technique on masonry walls against earthquakes, shake table tests have been conducted using retrofitted and non-retrofitted 1/4 scaled masonry houses with sinusoidal ground motion inputs (Meguro et al. [28]). According to the test, retrofitted masonry building could withstand over twice larger input energy than that of non-retrofitted specimen.
These methods seem to be relatively simple and easy to undertake, and utilize low-cost and readily-available materials, making them appropriate for application in householders with low income in developing countries. However, it is important to consider precautions against insect attack on bamboo.

\subsection{Retrofitting of URM Buildings against Tsunami and Flooding}

Because there are similar causes of effect by tsunami and flooding as by hydrostatic, hydro dynamic, impulsive, impact and buoyancy forces, same techniques can be used to strengthen the URM buildings against them. Retrofitting techniques should include anchoring the building or ensuring that the building itself is heavy enough against buoyancy forces and pressure. Also mechanical connections between the floor system and foundation must resist vertical and horizontal forces induced by flood and tsunami. Introducing the bracing members to the walls facing sea and minimizing the wall lengths can effectively reduce the flexural stresses developed by lateral pressure.

As suggested by Maheshwari et al. [26] bending failure caused by hydrostatic forces of tsunami could only be avoided by using reinforced walls designed for lateral forces of tsunami. To fulfil this purpose, retrofitting techniques of reinforcement such as bamboo, PP-band mesh, FRP which proved as seismic resistant may be effectively used. Increased wall thicknesses will enhance the overall resistance of the structure and $225 \mathrm{~mm}$ thick walls are suitable instead of $113 \mathrm{~mm}$ thick walls which are not suitable for structures in coastal zone having a threat of tsunami loading.

Kreibich et al. [24] have shown that, building a flood adapted house structure, e.g. using an especially stable building foundation or water proof sealing the cellar, is generally quite expensive. These structures can fail especially during extreme floods. However, steel frame and brick buildings tend to be less susceptible to collapse than those built with other materials. Water proof dry wall will hold up for long periods of inundation. To prevent penetration of surface water and ground water, any openings in the building must be raised or sealing measures must be implemented. Buildings can be sealed by using bitumen or strips of plastic or by constructing the base and walls of buildings using concrete that is almost non-permeable. The maximum height of water 
proofing should be approximately one meter above the ground.

\section{Discussion}

A structure adequately resists the forces applied to it if there is a suitable path for the force to follow, from the source of the force to the soil below the foundation and each part of the structure, that is, various connections - the walls, the foundation and even the soil, are sufficiently strong to withstand the effect of the inertial force, generally induced by externally applied forces. To enable the house to withstand the inertial forces due to strong ground motion without any damage being done to it, various parts of the house must be larger than they are now. However, it would be very costly to make them large. Instead of that, the magnitude of the inertial force can be very significantly reduced if the parts of the house which resist the inertial force can be made "ductile". Unfortunately, masonry blocks alone cannot be made ductile as they are made from brittle materials. Ductility in buildings can be achieved by placing ductile materials at certain places so that relevant parts of the building (walls, beams and columns) achieve sufficient level of ductility. However, materials cannot achieve $100 \%$ ductility and hence cracks will develop, but the building will not collapse.

Steel, PP-bands, bamboo and also rubber are ductile materials which can be used in retrofitting URM walls against natural disasters. The mesh reinforcement of these materials is said to be more effective rather than the use of as steel rods, bamboo poles, PP-strips and rubber tires. The distribution the meshes of ductile materials on the wall imparts beneficial properties of those materials to the masonry. This advantage can also be enhanced by embedding of meshes into brittle mortar as mentioned under the retrofitting technique of PP-band mesh reinforcement by Sathiparan et al. [33] and according to Clarke and Sharma [10].

The main effect of the external vertical and horizontal PP-band mesh is to restrain the separated sections of masonry allowing for redistribution of the load within the masonry itself. Vertical bands apply normal compression once sliding of rows occurs, resulting in increasing the masonry's frictional resistance to shear sliding. Through friction, energy from alien stresses is dissipated. Vertical bands also redistribute the load eliminating the concentration of load at particular regions but allowing deformation of wall panel. Horizontal bands directly bear load by resisting the separation of bricks within the same row allowing vertical bands to keep redistribution of the load over long period preventing/ delaying loss of debris. Both types of bands together give an improving of ductility with rigid box like action of enclosures. Further investigation should be focused on reducing stress which causes masonry corner cracking and separations and effect of real dwellings subjected to dynamic loads or reversed loads.

Steel mesh reinforcement in ferrocement casing improves ductility and energy dissipation and redistribute lateral loads applied to wall as discussed in PP-band methods. Compared to PP-band reinforcement, ferrocement improves compression strength of masonry walls leading to enhance their ultimate load bearing ability and tensile strength in higher amount. Ferrocement casing also delays crack originating or appearing while PP-band reinforcement gives their distribution on seismic resistance for masonry walls after first crack created on the walls. Compared with conventional reinforced concrete, ferrocement is reinforced in two directions; therefore, it may have homogenous isotropic properties. Because the specific surface of ferrocement reinforcement is higher than that of reinforced concrete, ferrocement generally has a high tensile strength and high modules of rupture. Therefore larger bond forces develop with matrix resulting in average crack spacing and crack width of smaller magnitude than that of URM walls and even conventional reinforced concrete. However, the premature cracking can occur if the excessive mortar thickness applied to cover wire mesh or the ferrocement is not properly cured (Sha [35]). Preventing the delamination of ferrocement casing, increasing of reinforcement into ferrocement skin, using an alternative material as reinforcements instead of steel and resistance of ferrocement strengthening of wall panel for both in-plane and out-of-plane should be focused in further investigations.

The retrofitting method used in 3I masonry specimen presented in Table 1, improves the flexural tensile strength of the wall. External horizontal bamboo poles restrain bending about vertical axis of the wall and tend to reduce flexural tension normal to bed joints and 
external vertical bamboo poles restrain bending about horizontal axis of the wall and tend to reduce flexural tension parallel to bed joints. Therefore, this combination restrains both inplane and out-of-plane bending of the structure. Internal horizontal chicken wire meshes redistribute the in-plane shear load/stress along the mortar bed joint improving diagonal tensile strength and shear strength against bed joint failure. The connection of ring beam on top of the wall resists the uplifting forces and shear forces and it applies normal compression together with vertical bamboos to resist shear sliding along mortar bed joints by increasing frictional resistance. Due to downward restraining force applied to top of the wing walls as mentioned in Section 3.1.3, overturning on walls and axial load resulted from overturing are prevented and wing walls acted as in-plane shear walls which resist lateral loads. This action lead to transfer the bulk of dynamic loads simulated in the test on out-of-plane long wall and corners of the specimens so that effectiveness of bamboo reinforcement as out-of-plane load resisting technique could be effectively tested. The external vertical and horizontal bamboo reinforcement, internal horizontal chicken wire mesh reinforcement and a ring beam altogether create an integrated matrix which restrain movement, and absorb, dissipate and redistribute energy within the structure. The behaviour of URM walls reinforced by external bamboo strip mesh reinforcement with different angles for in-plane and out-of-plane strengthening should be the focus of further investigation.

The application of surface finishing after the retrofitting of URM walls gives a beneficial effect in residual strength (as mentioned by Sathiparan et al. [33] in section 3.1.2) as it fills the gap between mesh and wall. This phenomenon is common in any situation of retrofitting of a building by any kind of material due to which proper application of external plaster or surface finishing fill gap between the wall and the retrofitting material and even makes a bond between them.

It is important to repair existing or damaged buildings before applying a new retrofitting on them, because repairing retains the original shape of the structure treating cracks and deterioration in them. As mentioned by Agarwal and Shrikhande [1], injection of cement grout containing admixtures or epoxy with and without inserting of reinforcement is recommended for hairline cracks and 5-20 mm wide cracks, respectively. In the case of $20 \mathrm{~mm}$ wide cracks or wall material dislodging, cement grouting (with through stone/bond stone for stone masonries) may be effectively used. Deteriorated or damaged units/bricks should be replaced by new ones of same appearance and material property. Mortar deteriorated due to its poor quality must be strengthened by repointing technique.

\section{Conclusions}

In Sri Lanka, natural disasters such as minor earthquakes, tsunami and storm surges, floods, cyclones and landslides are generally encountered. Weather changes showed that not only landslides and floods but also extreme wind events frequently occur. Forces induced by these effects on URM walls were identified as lateral loads including in-plane and out-ofplane induced by earthquakes and hydrostatic, hydrodynamic, impulsive, impact and buoyancy forces induced commonly by tsunamis and floods.

Most of domestic buildings in Sri Lanka are constructed by using unreinforced masonry (URM) units. These URM buildings were frequently collapsed due to natural disasters. The most important weaknesses of the damaged masonry structures were the lack of interlocking units between external and internal wythes of the wall sections and the lack of connection between crossing walls. Possible failures of structures were identified as in-plane failure, out-of-plane failure and connection failure. The main in-plane failure mechanisms of URM walls due to earthquake actions are identified as shear failure, sliding failure, rocking failure and toe crushing while out-of plane failures consist of vertical centre breaking on main wall perpendicular to the earthquake and vertical corner cracking on intersection of main wall and bracing walls. Bending, sliding, overturning, cracking by diagonal tension and crushing by diagonal compression are the failures induced by tsunami loading. It can be concluded that, failures due to flooding are also similar to those by tsunami where almost both of them induce similar type of forces in varying magnitudes acting on URM buildings. Formation of openings near the corners of the walls was identified as another common problem where crack propagation is concentrated around these openings. 
Retrofitting of existing and damaged buildings to resist the forces induced by natural disasters is simple, cost effective and time saving than reconstruction of the building. The main objective of the retrofitting is to enhance the earthquake resistance of masonry structural elements, in order to avoid failure modes that manifest in brittle and unforeseen manner. There are numbers of retrofitting methods for URM buildings, including ferrocement, bamboo reinforcement, PP-band mesh reinforcement and FRP. Commonly bamboo and ferrocement retrofitting methods explained and discussed in this paper are very significant in using against earthquakes in order to either in-plane or out-of-plane loads. But it is important to study about newly introduced retrofitting techniques such as PP-band reinforcement for strengthening of wall behaviour for both loads at same time with same environment.

Use of low quality materials and construction techniques cause extensive damages to unreinforced masonry buildings even when the magnitude of the natural disaster is quite low where no damages or very limited cracks are expected. Because of less awareness of peoples living in rural areas, generally, the domestic/rural area buildings are subjected to above situations. The most deaths occurred because low quality URM buildings have suddenly collapsed without giving sufficient time to people to evacuate for safe areas. Increasing of public awareness about the importance of strength properties of URM buildings are also recommended.

\section{Acknowledgement}

The research is funded by the National Research Council under NRC 11-193. The authors wish to express their special thanks to National Research Council (NRC) for providing necessary funds to carry out this research work.

\section{References}

1. Agarwal, P., and Shrikhande, M., "Earthquake resistant design of structures", $4^{\text {th }}$ Edition, Prentice-Hall of India Private Limited, 2007.

2. Arya, A. S., "Non-engineered Construction in Developing Countries - An Approach towards Earthquake Risk Prediction", The 12 th World Conference on Earthquake Engineering (WCEE), Auckland, New Zealand, 30 January 2000.

3. Ashraf, M., Khan, A. N., Naseer, A., Ali, Qaisar and Alam basher, "Seismic Behaviour of Unreinforced and Confined Brick Masonry Walls before and after
Ferrocement overlay Retrofitting", International Journal of Architectural Heritage, 2012, vol. 06, no. 06, pp. 665-688.

4. Bartolome, A. S., Quiun, D., and Zegarra, L., “Effective System for Seismic Reinforcement of Adobe houses", $13^{\text {th }}$ World Conference on Earthquake Engineering (WCEE), Vancouver, Canada, 01-06 August 2004.

5. Bartolome, A. S., Quiun, D., and Zegarra, L., "Performance of Reinforced Adobe houses in Pisco, Peru Earthquake", 14 ${ }^{\text {th }}$ World Conference on Earthquake Engineering (WCEE), Beijing, China, 12-17 October 2008.

6. Blonde,t M., Garcia, G. V., and Brzev, S., EarthquakeResistant Construction of Adobe Buildings: A Tutorial, 2003, (available online http://www.worldhousing.net/uploads/WHETutorial_Adobe_English.p df [accessed on 12/06/2012]).

7. Blondet, M., Vargas, J., and Tarque, N., "Low-Cost Reinforcement of Earthen houses in Seismic Areas", The 14th World Conference on Earthquake Engineering, Beijing, China, 12-17 October 2008.

8. Boen, T., “Earthquake Resistant Design of Non-engineered Buildings in Indonesia", 2001, (available online http://www.buildingtrustinternational.org/Indonesia n\%20Earthquake\%20Resistant\%20Design.pdf [accessed on 23/05/2012]).

9. Caraballo-Nadal, N. C., Zapata-Lopez, R. E., and Pagan-Trinidad, I., "Building Damage Estimation due to Riverine Floods, Storm Surges and Tsunamis: a Proposed Methodology", Fourth LACCEI International Latin American and Caribbean Conference for Engineering and Technology (LACCET),Mayaguez, Puerto Rico,21-23 June 2006.

10. Clarke, R., P., and Sharma, A. K., "The Earthquake Strengthening of Single-Storey Unreinforced Block Masonry houses in Trinidad and Tobago using ferrocement", 1998, (available online http:// richardpclarke.tripod.com/hurri/manual.pdf [accessed on 27/05/2012]).

11. D'Ayala, D., "Unreinforced Brick Masonry Construction", 2011, (available online http://www.worldhousing.net/wp-

content/uploads/2011/08/Type_Brick.pdf [accessed on $27 / 06 / 2012])$.

12. De Sliva, L., "Shifting of Tectonic Plates Cause for Tremors", Sunday Observer, 19 April 2012, (available online

http://www.sundayobserver.lk/2009/04/19/new13.a sp [accessed on 19/04/2012])

13. Dias, P., Dissanayake, R., and Chandrathilake, R., "Lessons learned from Tsunami Damage in Sri Lanka", Proceeddings of ICE - Civil Engineering, pp. 7481.

14. Dissanayake, C. B., "A new plate boundary near Sri Lanka: implication for future geohazards", Journal of Natural Science Foundation, Sri Lanka, Vol.33, No.1, 2005, pp. 5-8.

15. Dowling, D., Samali, B., and Li, J., "An Improved Means of Reinforcing Adobe Walls - External Vertical 
Reinforcement", Sismo Adobe, PUCP, Lima, Peru, 16-19 May 2005.

16. Ehshani, M., and Saadatmanesh, H., "Seismic Retrofit of URM walls with Fiber Composite", TMS Journal, 1996, pp. 63-72.

17. Ehshani, M. R., Saadatmanesh, H., and VelazquezDimas, J. I., "Behaviour of Retrofitted URM Walls under Simulated Earthquake Loading", Journal of Composite for Construction, 1999, pp. 134-142.

18. ElGawady, M. A., Lestuzzi, P. and Badoux, M., "Aseismic Retrofitting of Unreinforced Masonry Walls using FRP", ELSEVIER, Composites: Part B 37, 2006, pp. 148-162.

19. ElGawady, M. A., Lestuzzi, P. and Badoux, M., "Retrofitting of Masonry walls using Shotcrete", New Zealand Society for Earthquake Engineering (NZSEE) Conference, Napier, New Zealand, 10-12 March 2006.

20. Kaplan, H., Yilmaz, S., Nohutcu, H., Cetinkaya, N., and Binici, H., "Experimental Study on the use of Old Tires for Seismic Strengthening of Masonry Structures", The 14 ${ }^{\text {th }}$ World Conference on Earthquake Engineering, Beijing, China, 12-17 October 2008.

21. Keerthisinghe, A. I., "Environmental Protection and Sustainable Development in Sri Lanka", The Sunday Leader, 9 July 2012, (available online http://www.thesundayleader.lk/2012/07/08/enviro nmental-protection-and-sustainable-development-insri-lanka/ [accessed on 08/07/2012]).

22. Kelman, I. and Spence, R., "A Limit Analysis of Unreinforced Masonry Failing under Flood Water Pressures", Masonry International, 2003, Vol. 16, No. 2, pp. 51-61.

23. Khazai, B., Franco, G., Ingram, J. C., Rio, C. R. D., Dias, P., Dissanayake, R., Chandratilake, R., and Kanna, S. J., "Post-December 2004 Tsunami Reconstruction in Sri Lanka and its Potential Impacts on Future Vulnerability", Earthquake Spectra, 2006, Vol.22, No.S3, pp. S829-S844.

24. Kreibich, H., Thieken, A. H., Petrow, T., Muller, M. and Merzl, B., "Flood Loss Reduction of Private Households due to Building Precautionary Measures Lessons Learned from the Elbe flood in August 2002", Natural Hazards and Earth System Sciences, 2005, Vol. 5, pp. 117-126.

25. Macabuag, J., Bhattacharya, S. and Blakeborough, T., "Extending the Collapse Time of Non-Engineered Masonry Buildings under Seismic Loading", The $14^{\text {th }}$ World Conference on Earthquake Engineering, Beijing, China, 12-17 October 2008.

26. Maheshwari, B. K., Sharma, M. L. and Narayan, J. P., "Structural Damages on the Coast of Tamil Nadu due to Tsunami Caused by December 26, 2004 Sumatra earthquake", ISET Journal of Earthquake Technology, June-September 2005, Vol. 42, No. 2-3, pp. 63-78.

27. Mayorca, P. and Meguro, K., "Proposal of an Efficient Technique for Retrofitting Unreinforced Masonry Dweellings", 13 $3^{\text {th }}$ World Conference on Earthquake
Engineering (WCEE), Vancouver, Canada, 01-06 August 2004, Paper No. 2431.

28. Meguro, K., Soti, R., Navaratnaraj, S. and Numada, M., "Dynamic Behaviour of Masonry houses Retrofitted by Bamboo Band Mesh", The 15th World Conference on Earthquake Engineering, Lisbon, Portugal, 24-28 September 2012.

29. Rajasingham, K. T., "Saving Sri Lankan Lives through Open Data", Asian Tribune, 14 September 2012, Vol. 11, No. 532, (available online http:/ / www.asiantribune.com/news/2012/09/13/sa ving-sri-lankan-lives-through-open-data [accessed on 11/07/2012]).

30. Renuka, I. H. S., and Lewangamage, C. S., "Structural Aspects of Post Tsunami Domestic Constructions in Sri Lanka", Annual Research Journal of SLSAJ, Sri Lanka, 2011, Vol. 11, pp. 65-71.

31. Rogers, C.D.P.E., "Structural damage due to floods", 2012, (available online http://www.rimkus.com/craig_rogers_article_in_clai ms_magazine [accessed on 11/07/2012]).

32. Saatcioglu, M., Ghobarah, A. and Nistor, I., Reconnaissance Report on the December 26, 2004 Sumatra earthquake and tsunami, 2005, (available online

http://www.caee.uottawa.ca/Publications/PDF\%20fi les/CAEE\%20Sumatra\%20Report.pdf [accessed on 27/062012])

33. Sathiparan, N., Mayorca, P., Nesheli, K. N., Guragain, R. and Meguro, K., "Experimental Study on In-plane and out-of-plane Behaviour of Masonry Wallets Retrofitted by PP-band meshes", Seisan-Kenkyu, 2005, vol. 57, no. 06, pp. 530-533.

34. Shah, A. A., "Applications of ferrocement in Strengthening of Unreinforced Masonry Columns", International Journal of Geology, 2011, vol. 5, no. 01, pp. 21-27.

35. Shahzada, K., Javed, M., Alam, B., Khan, M., Ali, Z., Khan, H., and Shah, S. S. A, "Strengthening Brick Masonry against Earthquake Loading", International Journal of Advanced Structures and Geotechnical Engineering, July 2012, Vol. 01, No. 01, pp. 10-14.

36. Velazquez-Dimas, J. I., Ehsani, M. R. and Saadatmanesh, H., "Out-of-plane Behaviour of Brick Masonry walls Strengthened with Fibre Composites", ACI Structural Journal, May-June 2000, Vol. 97, No. 3, pp. 377-387.

37. Webster, F.A., "Earthen Structures: Assessing Seismic Damage, Performance and Interventions", Terra Literature Review: An Overview of Research in Earthen Architecture Conservation, 2008, pp.69-78, (available online

http://www.getty.edu/conservation/publications_re sources/pdf_publications/terra_lit_review.pdf [accessed on 10/07/2010]). 